\title{
A tight balance of Karyopherin $\beta 1$ expression is required in cervical cancer cells
}

\author{
Sarah Carden ${ }^{1}$, Pauline van der Watt ${ }^{1}$, Alicia Chi ${ }^{1}$, Aderonke Ajayi-Smith ${ }^{1}$, Katie Hadley ${ }^{1}$ and Virna D. Leaner ${ }^{1,2^{*}}$ (D)
}

\begin{abstract}
Background: Karyopherin $\beta 1$ (Kpn $\beta 1)$ is the main nuclear import protein involved in the transport of cargoes from the cytoplasm into the cell nucleus. Previous research has found Kpn $\beta 1$ to be significantly overexpressed in cervical cancer and other cancer tissues, and further studies showed that inhibition of Kpn $\beta 1$ expression by siRNA resulted in cancer cell death, while non-cancer cells were minimally affected. These results suggest that Kpn $\beta 1$ has potential as an anticancer therapeutic target, thus warranting further research into the association between Kpn $\beta 1$ expression and cancer progression. Here, the biological effects associated with $\mathrm{Kpn} \beta 1$ overexpression were investigated in order to further elucidate the relationship between Kpn $\beta 1$ and the cancer phenotype.

Methods: To evaluate the effect of Kpn $\beta 1$ overexpression on cell biology, cell proliferation, cell cycle, cell morphology and cell adhesion assays were performed. To determine whether Kpn $\beta 1$ overexpression influences cell sensitivity to chemotherapeutic agents like Cisplatin, cell viability assays were performed. Expression levels of key proteins were analysed by Western blot analysis.

Results: Our data revealed that Kpn $\beta 1$ overexpression, above that which was already detected in cancer cells, resulted in reduced proliferation of cervical cancer cells. Likewise, normal epithelial cells showed reduced proliferation after Kpn $\beta 1$ overxpression. Reduced cancer cell proliferation was associated with a delay in cell cycle progression, as well as changes in the morphology and adhesion properties of cells. Additionally, Kpn $\beta 1$ overexpressing HeLa cells exhibited increased sensitivity to cisplatin, as shown by decreased cell viability and increased apoptosis, where p53 and p21 inhibition reduced and enhanced cell sensitivity to Cisplatin, respectively.
\end{abstract}

Conclusions: Overall, our results suggest that a tight balance of Kpn $\beta 1$ expression is required for cellular function, and that perturbation of this balance results in negative effects associated with a variety of biological processes.

Keywords: Karypherin $\beta 1$, Overexpression, Cancer biology

\section{Background}

The Karyopherin protein superfamily consists of a large number of soluble transport factors that shuttle proteins and certain RNAs through the nuclear pore complex (NPC). Karyopherin $\beta 1(\mathrm{Kpn} \beta 1)$, the primary nuclear import protein in interphase cells, imports cargoes that

\footnotetext{
*Correspondence: Virna.Leaner@uct.ac.za

'Division of Medical Biochemistry and Structural Biology, Department of Integrative Biomedical Sciences, Institute of Infectious Disease and Molecular Medicine, SAMRC/UCT Gynaecological Cancer Research Centre, Faculty of Health Sciences, University of Cape Town, Cape Town, South Africa

${ }^{2}$ Division of Medical Biochemistry and Structural Biology, Faculty of Health Sciences, University of Cape Town, Observatory, Cape Town 7925, South
} Africa

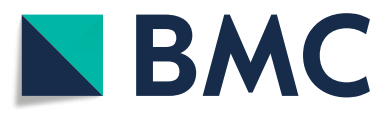

(c) The Author(s). 2018 Open Access This article is distributed under the terms of the Creative Commons Attribution 4.0 International License (http://creativecommons.org/licenses/by/4.0/), which permits unrestricted use, distribution, and reproduction in any medium, provided you give appropriate credit to the original author(s) and the source, provide a link to the Creative Commons license, and indicate if changes were made. The Creative Commons Public Domain Dedication waiver (http://creativecommons.org/publicdomain/zero/1.0/) applies to the data made available in this article, unless otherwise stated. contain a nuclear localisation sequence (NLS) across the nuclear membrane and into the nucleus [1]. In the classical nuclear import pathway, recognition of an NLS, which most commonly consists of a number of clusters of basic amino acids and is termed the classical NLS (cNLS), by a Karyopherin $\alpha(\mathrm{Kpn} \alpha)$ isoform is required for Kpn $\beta 1$-mediated nuclear import [2, 3]. After Kpn $\alpha$ binds to the NLS-containing cargo, forming a bridge between the cargo and $K p n \beta 1, K p n \beta 1$ interacts with nucleoporins (Nups) on the NPC to allow for transfer of the cargo through the channel. Once in the nucleus, binding of RanGTP results in dissociation of the trimeric complex and release of the cargo [4]. Kpn $\beta 1$ and Kpn $\alpha$ 
are then recycled back to the cytoplasm for another round of nuclear import. Alternatively to classical nuclear import, some cargoes are able to bind $K p n \beta 1$ directly (independent of Kpn $\alpha$; non-classical pathway), or utilise other members of the Karyopherin $\beta$ family for their nuclear import.

Studies have shown that in addition to its role as a nuclear importer, $\mathrm{Kpn} \beta 1$ has an equally vital set of roles during mitosis, acting as a negative regulator for various mitotic processes from spindle assembly and regulation to nuclear membrane and nuclear pore reformation, where in most cases it is counter-regulated by the small regulatory GTPase, Ran [5, 6]. Previous studies have shown that disruption of $\mathrm{Kpn} \beta 1$ expression (by loss of endogenous $\mathrm{Kpn} \beta 1$ through siRNA-mediated knockdown, or transient overexpression of $\mathrm{Kpn} \beta 1$ using plasmid-based transfection), resulted in the appearance of distinct mitotic defects, such as multipolar spindles, chromosome misalignment, and lagging or mis-segregation of chromosomes in anaphase/telophase [7-9]. These results suggest that a balance of Kpn $\beta 1$ expression may be necessary for correct cell functioning.

It has been shown that $\mathrm{Kpn} \beta 1$ expression is elevated in cervical cancer tissue, as well as a number of transformed and cancer cell lines, suggesting its association with the cancer phenotype [10-12]. We previously showed that inhibition of $\mathrm{Kpn} \beta 1$ protein expression leads to cancer cell death via apoptosis [10], and Kuusisto and Jans (2015) showed that faster growing tumour cells expressing high levels of $\mathrm{Kpn} \beta 1$ are more dependent on, or "addicted to", Kpn $\beta 1$ than their non-transformed counterparts [13]. These results demonstrate that increased expression, and thus activity, of $\mathrm{Kpn} \beta 1$ likely plays a role in cancer cell proliferation, making Kpn $\beta 1$ an attractive anticancer therapeutic target. Interestingly, siRNA-mediated knockdown of $K p n \beta 1$ leaves normal cells relatively unaffected $[9,10]$. It is possible that cancer cells have devised a mechanism to cope with their increased metabolic and proliferative demands by enhancing expression of various proteins, among them Kpn $\beta 1$, potentially explaining why depletion of Kpn $\beta 1$ has such negative effects. In contrast, it appears as if normal cells are less reliant on $\mathrm{Kpn} \beta 1$ for processes such as proliferation.

While a number of studies have revealed the importance of $\mathrm{Kpn} \beta 1$ in cancer cell survival and proliferation, and described its potential as an anticancer target, the precise role that $\mathrm{Kpn} \beta 1$ plays in cellular transformation and cancer progression is largely unclear. In this study, we investigated the biological effects associated with $\mathrm{Kpn} \beta 1$ overexpression in order to further elucidate the relationship between $\mathrm{Kpn} \beta 1$ and cancer progression. While it is evident from previous work that cancer cells require $\mathrm{Kpn} \beta 1$ for their proliferation and survival, it is unclear whether overexpression of Kpn $\beta 1$ provides a growth advantage to cancer cells, or leads to phenotypes associated with cellular transformation. In this study, we show that $\mathrm{Kpn} \beta 1$ overexpression in fact leads to negative effects associated with the functioning of cervical cancer cells, and thus a precise balance of Kpn $\beta 1$ expression and activity appears to be essential for the correct functioning of these cells. Disruption of this balance in either direction has detrimental effects on many cellular processes.

\section{Methods}

\section{Cell lines and cell culture}

The human cervical carcinoma cell lines, HeLa (ATCC CCL-2) and CaSki (ATCC CRL-1550), and normal primary (ARPE19) (ATCC CRL-2302) and immortalised (hTERT-RPE-1) (ATCC CRL-4000) epithelial cells were obtained from the American Type Culture Collection (ATCC). Cancer cells were cultured in Dulbecco's Modified Eagle's Medium (DMEM), supplemented with penicillin $(100 \mathrm{U} / \mathrm{ml})$, streptomycin $(100 \mu \mathrm{g} / \mathrm{ml})$ and $10 \%$ Fetal Calf Serum (FCS) (HiClone, Thermo Scientific, USA). Normal cells were cultured in DMEM/F12 media, supplemented with penicillin, streptomycin and 10\% FCS. hTERT-RPE-1 cells were maintained in the presence of $10 \mu \mathrm{g} / \mathrm{ml}$ Hygromycin B. Cells were incubated at $37^{\circ} \mathrm{C}$ in $5 \% \mathrm{CO}_{2}$. Cancer cell lines were authenticated by DNA profiling using the Cell ID system (Promega, USA).

\section{Generation of stable Kpn $\beta 1$ overexpressing cell lines}

The plasmid used for overexpression of Kpn $\beta 1$ (pEFIRES-Kpn $\beta 1$-EGFP) was generated by inserting SacI- and NotI-digested human Kpn $\beta 1$-EGFP, released from the plasmid pEGFP-Kpn $\beta 1$ (kind gift from Patrizia Lavia, Institute of Molecular Biology and Pathology, National Research Council of Italy, Rome, Italy) [7], into the pEFIRES plasmid (kind gift from Yosef Shaul, Weizmann Institute of Science, Israel) [14]. The pEFIRES plasmid was used in order to allow for both the Kpn 31 -EGFP fusion gene and the puromycin resistance gene to be transcribed as a single mRNA transcript. The presence of an internal ribosome entry site (IRES) upstream of the puromycin resistance gene ensures that puromycin-resistant clones express high levels of the recombinant protein, Kpn $\beta 1$-EGFP. pEFIRES-EGFP was used as a control. For the establishment of cells stably expressing Kpn $\beta 1$-EGFP, cells were transfected with the pEFIRES-EGFP and pEFIRES-Kpn $\beta 1-E G F P$ constructs using Genecellin Transfection Reagent (Celtic Molecular Diagnostics) or TransFectin Lipid Reagent (Bio-Rad), and thereafter positively transfected cells were selected with Puromycin (Calbiochem, Merck). Pools of stably transfected cells were maintained in $0.5 \mu \mathrm{g} / \mathrm{ml}$ Puromycin.

\section{Fluorescence microscopy}

To analyse EGFP-tagged protein localisation using fluorescent microscopy, cells were grown on glass coverslips 
and fixed in $4 \%$ paraformaldehyde. Coverslips were mounted onto glass slides using Mowiol. Images were captured using the AxioVision 4.7 software (Zeiss, Oberkochen, Germany) under $100 \mathrm{x}$ oil immersion.

\section{Western blot analysis}

Western Blot analyses were performed using rabbit anti-Kpn $\beta 1$ (H300) (Santa Cruz Biotechnology, sc-11367), mouse anti-GAPDH (0411) (Santa Cruz Biotechnology, sc-47724), rabbit anti-GFP (FL) (Santa Cruz Biotechnology, sc-8334), rabbit anti-Cyclin A (H-432) (sc-751), rabbit anti-Cyclin D1 (HD11) (sc-246), rabbit anti-pHisH3 (Ser-10)-R (Santa Cruz Biotechnology, sc-8656), rabbit anti-Mcl-1 (H-260) (Santa Cruz Biotechnology, sc-20679), rabbit anti-E-cadherin (H-108) (Santa Cruz Biotechnology, sc-7870), mouse anti-Vimentin (V-9) (Santa Cruz Biotechnology, sc-6260), rabbit anti-PARP1/2 (H-250) (Santa Cruz Biotechnology, sc-7150), mouse anti-p53 (DakoCytomation, M7001), rabbit anti-p21 (H-164) (Santa Cruz Biotechnology, sc-756), rabbit anti- $\gamma \mathrm{H} 2 \mathrm{AX}$ (Ser-139) (Cell Signaling, 2577S), and rabbit anti-TFIID (TBP) (N-12) (Santa Cruz Biotechnology, sc-204) antibodies.

\section{Luciferase assays}

To assay for NFAT luciferase activity, cells were transfected with 50 ng GFP-NFAT (Addgene plasmid \#24219; gift of Jerry Crabtree [15]), 50 ng NFAT-luciferase (Addgene plasmid \#10959; gift of Toren Finkel [16]), and 5 ng pRL-TK (encoding Renilla luciferase; Promega, USA). To assay for AP-1, NFKB p65 and p53 luciferase activity, cells were transfected with either $100 \mathrm{ng}$ AP1-luciferase reporter construct (containing four copies of the AP-1 binding site; gift of Michael Birrer [17]), 100 ng NFkB p65 luciferase reporter construct (containing 5 copies of the p65 binding site; Promega, USA) or 100 ng p53-luciferase reporter construct (Addgene plasmid \#16442; gift of Bert Vogelstein [18]), as well as $5 \mathrm{ng}$ pRL-TK. For NFkB p65 luciferase assays, cells were stimulated with $0.5 \mu \mathrm{M}$ PMA (Sigma-Aldrich, USA) for $3 \mathrm{~h}$, at $24 \mathrm{~h}$ post transfection. Luciferase activity was assayed using the Dual-Luciferase Reporter assay system (according to the manufacturer's instructions; Promega, USA). Luciferase readings measured using the Veritas microplate luminometer (Promega, USA) were normalised to Renilla luciferase readings.

\section{Trypan blue cell viability assays}

To assay for the number of viable cells, cells were trypsinised and incubated with 0.4\% Trypan Blue (Merck Millipore, USA). Viable (white) and non-viable (blue) cells were counted using a haemocytometer, and the number of live cells at various time points was recorded.

\section{MTT proliferation assays}

To allow for anchorage-independent growth, cells were resuspended in 1\% methyl cellulose-containing media and were plated onto Poly (2-hydroxyethyl methacrylate) (Poly-HEMA) (Sigma-Aldrich, USA) coated 96-well plates. The number of colonies formed at various time points post plating were measured using the MTT reagent (according to the manufacturer's instructions; Sigma-Aldrich, USA).

Adherent growth as a result of $\mathrm{Kpn} \beta 1$ overexpression was determined using the MTT proliferation assay (according to the manufacturer's instructions; Sigma-Aldrich, USA).

For the analysis of the effect of p53 and p21 inhibition on Cisplatin-induced cell death, cells were either co-treated with Pifithrin $\alpha$ (Sigma) and Cisplatin, or transfected with control or p21 siRNA (Santa Cruz Biotechnology), using Transfectin (BioRad, USA) transfection reagent, and treated with Cisplatin $48 \mathrm{~h}$ post-transfection. MTT assays were performed $24 \mathrm{~h}$ after Cisplatin treatment.

\section{Cell cycle analysis}

Cells were synchronised with $2 \mathrm{mM}$ Thymidine (Sigma-Aldrich, USA), and released into fresh media. Cells (and floaters) were harvested and fixed in 100\% ethanol overnight. Fixed cells were treated with $50 \mu \mathrm{g} / \mathrm{ml}$ RNase and stained with propidium iodide. Cell cycle profiles were analysed using a BD Accuri Flow Cytometer (Beckman Coulter, Fullerton, CA, USA). Quantification of the percentage of cells at different cell cycle stages was performed using the ModFit LT 3.3 software (Verity Software House, USA).

\section{Phalloidin staining of F-actin}

Cells were fixed and washed twice in $0.04 \%$ PBST before blocking in 1\% BSA for $30 \mathrm{~min}$. Actin was labeled with $50 \mathrm{ng} / \mathrm{ml}$ Phalloidin-Tetramethylrodamine B isothiocyanate (Phalloidin) (Sigma-Aldrich, USA) in 1\% BSA for $30 \mathrm{~min}$ at room temperature. Cell nuclei were stained with $100 \mathrm{ng} / \mathrm{ml}$ DAPI and coverslips mounted onto glass slides using Mowiol. Phalloidin images were viewed using the Zeiss Inverted Fluorescence Microscope under 100 x oil immersion and images captured using the AxioVision 4.7 software (Zeiss, Germany).

\section{Cell adhesion assays}

Cells were plated on uncoated plates and allowed to adhere for $1 \mathrm{~h}$ at $37^{\circ} \mathrm{C}$. Thereafter, the medium was removed from all wells and 'washed' cells were rinsed twice with PBS before fixation of all cells in $0.5 \mathrm{ml}$ fixation solution (acetic acid/methanol (1:7)) for $5 \mathrm{~min}$ followed by staining with $0.5 \%$ crystal violet solution for $2 \mathrm{~h}$ at room temperature. Plates were rinsed in water and left to dry overnight. The number of cells over various fields of view were counted using a light microscope and normalized to 
the number of 'unwashed' cells, in order to control for total cells plated.

\section{In vitro scratch wound healing assay}

Cells were grown to approximately 90\% confluence, wounded (at time $0 \mathrm{~h}$ ) using a pipette tip, and treated with $5 \mu \mathrm{g} / \mathrm{ml}$ Mitomycin C (Sigma). To record scratch wound closure, images were captured at $0,3,6$ and $24 \mathrm{~h}$ time points and gap size measured. Each time point was normalized to the time 0 gap size.

\section{$\mathrm{IC}_{50}$ determination assays}

For the determination of drug $\mathrm{IC}_{50}$ values, cells were treated with varying concentrations of cisplatin for a period of $48 \mathrm{~h}$, after which the MTT assay was performed (according to the manufacturer's instructions; Sigma-Aldrich, USA). $\mathrm{IC}_{50}$ curves were generated using GraphPad Prism (GraphPad Software Inc., USA).

\section{Nuclear and cytoplasmic protein fractionation}

Cells were grown to $80 \%$ confluency, trypsinised, and the cell pellet resuspended in at least 6 volumes harvest buffer (10 mM HEPES, pH 7.9, $50 \mathrm{mM} \mathrm{NaCl}, 0.5 \mathrm{M} \mathrm{Su}-$ crose, $0.1 \mathrm{mM}$ EDTA, $0.5 \%$ Triton X-100). Lysates were incubated on ice for $5 \mathrm{~min}$, followed by centrifugation. The supernatant was kept aside as the cytoplasmic fraction, and the pellet was resuspended in $500 \mu \mathrm{l}$ buffer A (10 mM HEPES, pH 7.9, $10 \mathrm{mM} \mathrm{KCl,} 0.1 \mathrm{mM}$ EDTA, $0.1 \mathrm{mM}$ EGTA). Centrifugation was performed followed by resuspension of the pellet in 4 volumes buffer $\mathrm{C}$ (10 mM HEPES, pH 7.9, $500 \mathrm{mM} \mathrm{NaCl}, 0.1 \mathrm{mM}$ EDTA, $0.1 \mathrm{mM}$ EGTA, 0.1\% NP40). Samples were vortexed for $15 \mathrm{~min}$, followed by centrifugation, whereupon the supernatant was kept as the nuclear extract.

\section{Statistical analysis}

For all data comparisons, the Student's t test was performed using Microsoft Excel. Data was presented as the mean \pm SEM. Unless where otherwise stated, experiments were performed in triplicate or quadruplicate and repeated at least three independent times. A $p$ value of $<0.05$ was considered statistically significant.

\section{Results}

Exogenous Kpn $\beta 1$ enhances the nuclear import of known Kpn $\beta 1$ cargoes in cervical cancer cells

$\mathrm{HeLa}$ and CaSki cell lines stably expressing Kpn $\beta 1$-EGFP were established to study the effects of Kpn $\beta 1$ overexpression on various biological phenotypes. To confirm the presence of EGFP and Kpn $\beta 1$-EGFP, cells were visualised using fluorescence microscopy. HeLa and CaSki cells expressing EGFP showed diffuse fluorescence that was both cytoplasmic and nuclear (predominantly nuclear), probably due to the fact that EGFP is small $(\sim 32 \mathrm{kDa})$ and can thus passively diffuse across the NPC. Cells expressing Kpnß1-EGFP showed nuclear and cytoplasmic localization of exogenous $\mathrm{Kpn} \beta 1$, as well as a distinct perinuclear band (Fig. 1a). This correlates with Kpn $\beta 1$ 's function as a nuclear transport protein. Western blot analysis revealed that Kpn $\beta 1$-EGFP was expressed at approximately equivalent levels to that of endogenous $\mathrm{Kpn} \beta 1$ in both $\mathrm{HeLa}$ and CaSki cells (Fig. 1b).

To investigate whether overexpression of $\mathrm{Kpn} \beta 1$ leads to enhanced $\mathrm{Kpn} \beta 1$ functionality (i.e. $K p n \beta 1$-mediated nuclear import), the nuclear activity of various $K p n \beta 1$ cargoes was assayed in HeLa EGFP and Kpnß1-EGFP cells. Luciferase assays were performed to assay for nuclear activity of Kpn $\beta 1$ cargoes NFAT [14], AP-1 [19], NFkB p65 [20] and p53 [21, 22]. HeLa cells stably expressing Kpn $\beta 1$-EGFP showed a significant increase in the nuclear activity of NFAT (Fig. 1c), AP-1 (Fig. 1d), PMA-induced NFkB p65 (Fig. 1e) and p53 (Fig. 1f), thereby suggesting that overexpession of $\mathrm{Kpn} \beta 1$, by expression of exogenous Kpn $\beta 1$-EGFP, leads to increased nuclear activity of Kpn $\beta 1$ cargo proteins.

\section{Overexpression of $\mathrm{Kpn} \beta 1$ results in reduced proliferation of cervical cancer and normal epithelial cells}

Since high levels of $\mathrm{Kpn} \beta 1$ are required for cancer cell survival and proliferation [10], it was anticipated that overexpression might confer a further growth advantage. To determine the effect of $K p n \beta 1$ overexpression on cell proliferation, trypan blue cell viability assays were performed. Interestingly, results revealed that overexpression of $\mathrm{Kpn} \beta 1$ resulted in a significant reduction in the number of adherent HeLa and CaSki cells (Fig. 2a, b). The number of live cells decreased and minimal dead cells were observed, suggesting an inhibition of proliferation rather than induction of cell death. When the effect of $\mathrm{Kpn} \beta 1$ overexpression on cell proliferation was expanded to look at cells grown under anchorage-independent conditions, a similar result was observed; a significant reduction in proliferation of HeLa and CaSki cells stably expressing Kpnß1-EGFP (Fig. 2c, d).

Since fast proliferating cancer cells already display high levels of Kpn $\beta 1$, it was next determined whether normal epithelial cells transfected with exogenous Kpn $\beta 1$ might display increased proliferation. Surprisingly, Kpn $\beta 1$ overexpression in the primary and immortalised epithelial cell lines, ARPE-19 and hTERT-RPE-1, respectively, resulted in significantly reduced cell proliferation, similar to that observed in the cancer cell lines, even after only modest overexpression (Fig. 2e, f). These results suggest that $\mathrm{Kpn} \beta 1$ overexpression alone is not beneficial to cells, and in fact inhibits cell proliferation. 


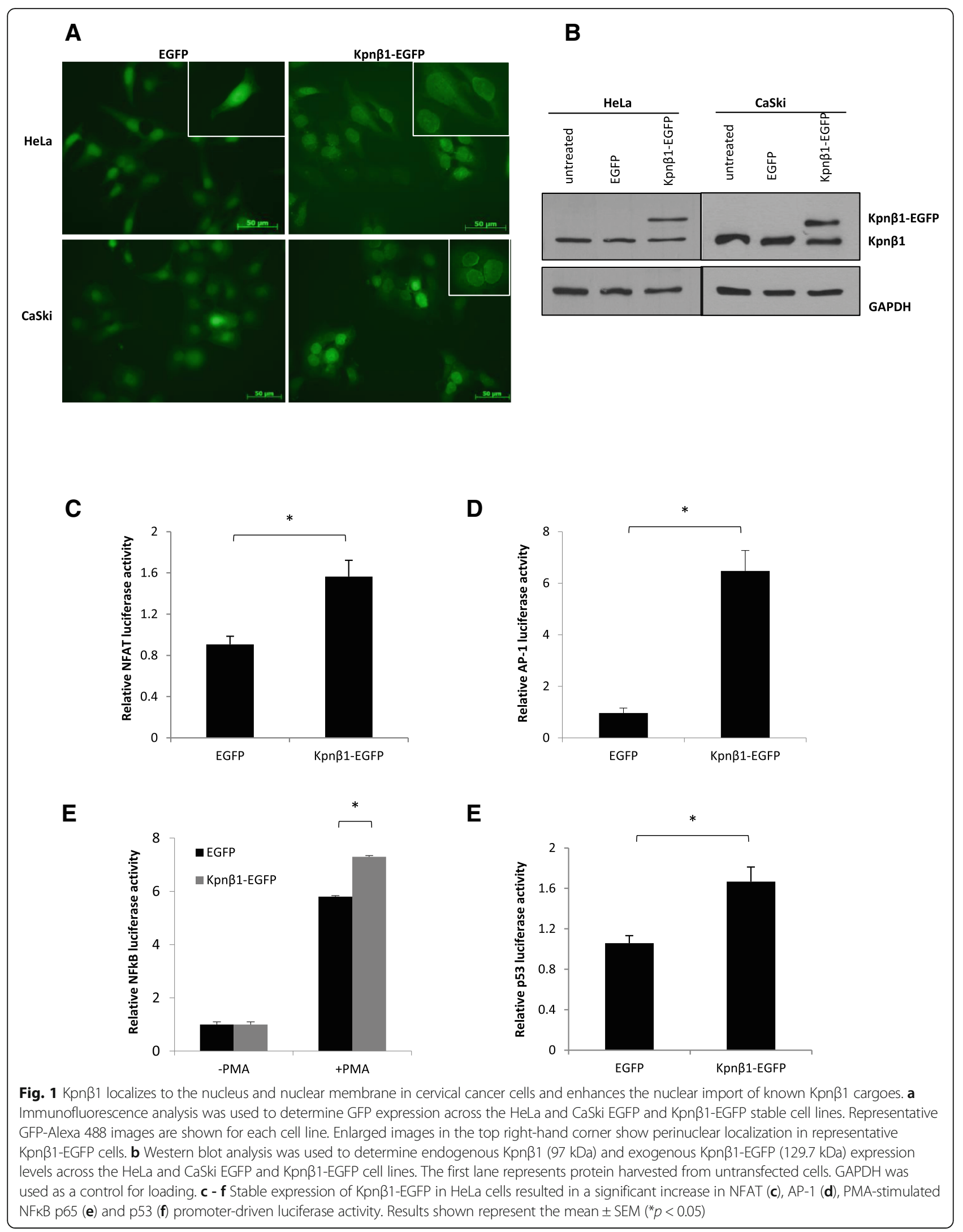




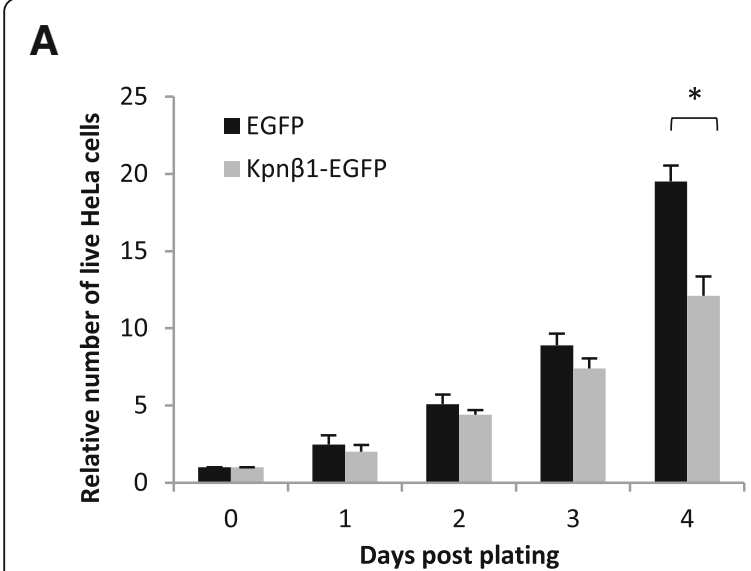

B

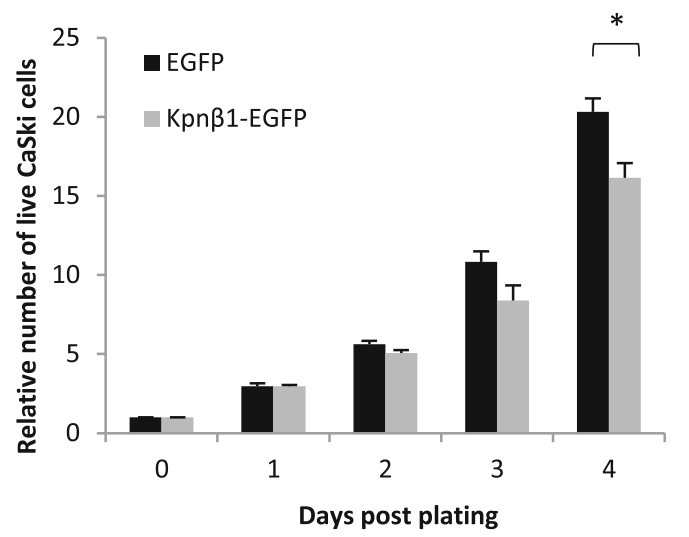

C

D
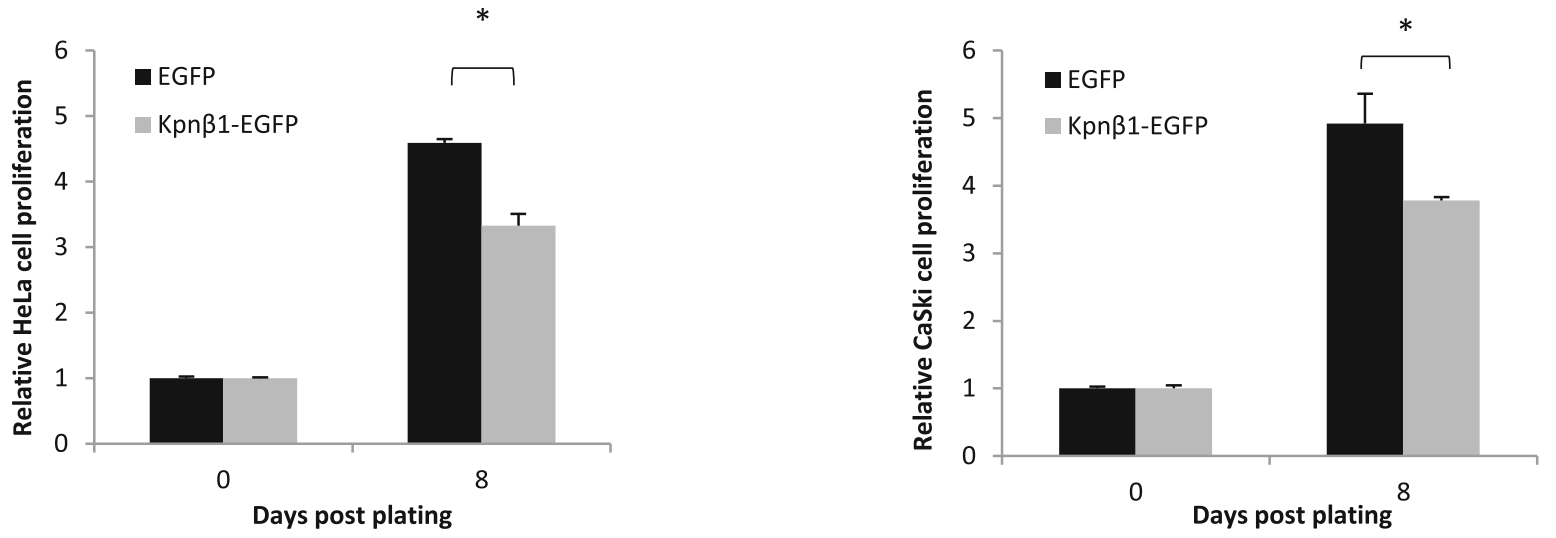

E

$\mathbf{F}$
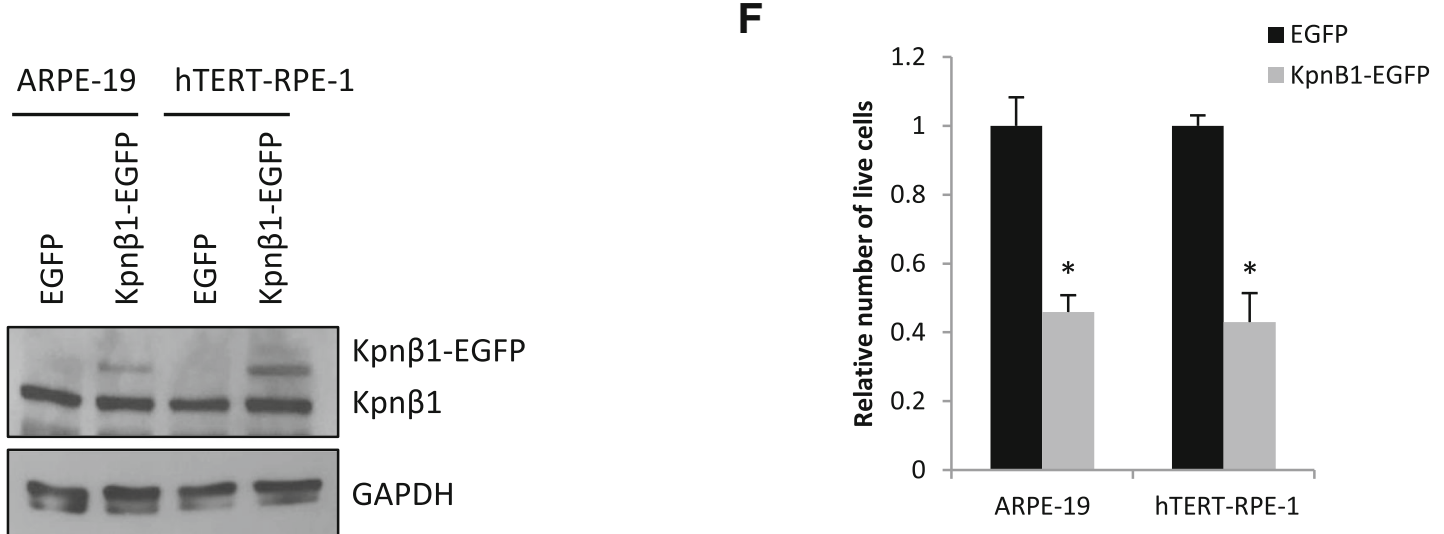

Fig. 2 (See legend on next page.) 
(See figure on previous page.)

Fig. 2 Overexpression of $\mathrm{Kpn} \beta 1$ results in reduced proliferation of cervical cancer and normal epithelial cells. a, b Trypan Blue assays revealed a significant reduction in the number of live HeLa (a) and CaSki (b) cells expressing Kpn $\beta 1$-EGFP compared to EGFP. Cells were counted for a period of up to 4 days post plating. $\mathbf{c}, \mathbf{d}$ MTT cell proliferation assays reveal a significant reduction in the anchorage-independent proliferation of HeLa (c) and CaSki (d) cells stably overexpressing Kpnß1. Cells growing adherently were plated in 1\% methylcellulose-containing media into 96-well plates coated in $12 \mathrm{mg} / \mathrm{ml}$ poly-HEMA. Cell proliferation was assayed by the addition of the MTT reagent for a period of up to 8 days. Results shown represent the mean \pm SEM ( $\left.{ }^{*} p<0.05\right)$. e Western blot analysis reveals moderate Kpn $\beta 1$ overexpression in ARPE-19 and hTERT-RPE-1 normal epithelial cell lines. $\mathbf{f}$

Trypan blue assays show a significant reduction in ARPT-19 and hTERT-RPE-1 cell number $96 \mathrm{~h}$ after transient Kpn $\beta 1$ overexpression. Results shown represent the mean \pm SEM $\left({ }^{*} p<0.05\right)$

\section{Overexpression of $\mathrm{Kpn} \beta 1$ results a delay in cervical cancer cell cycle progression}

Due to the suppression of cell proliferation upon exogenous $\mathrm{Kpn} \beta 1$ expression, the effects of $\mathrm{Kpn} \beta 1$ overexpression on cell cycle progression were next investigated. Using FACS analysis, asynchronous cells revealed only minor changes when Kpn $\beta 1$ was overexpressed (data not shown), but despite this, it was possible that the cell cycle was being arrested at several phases after Kpn $\beta 1$ overexpression. Various cell cycle markers in these cells were thus investigated by western blot analysis. Levels of Cyclin A, Cyclin D1 and pS10-Histone-H3 (pHisH3), a marker for cells in mitosis, were all slightly elevated in the HeLa and CaSki Kpn 31 -EGFP cells (Fig. 3a), suggesting multiple phases of the cell cycle were affected by Kpn $\beta 1$ overexpression. To investigate this further, HeLa EGFP and Kpn $\beta 1$-EGFP cells were synchronized to late G1/early S phase using a thymidine block and harvested at various time points post release into complete medium. FACS analysis of synchronized cells revealed that Kpn $\beta 1$ overexpression resulted in a prolonged delay or progression from the G1/S block, as Kpn $\beta 1$-EGFP expressing cells progressed through the cell cycle much slower than the EGFP expressing cells (Fig. 3b). Quantification of the percentage of HeLa EGFP and Kpn 31 -EGFP cells in each phase of the cell cycle showed that while $50 \%$ of EGFP expressing cells had exited G1 phase and entered S phase by approximately $3 \mathrm{~h}$, it took approximately $6 \mathrm{~h}$ for the Kpn $\beta 1$-EGFP expressing cells to reach the same stage (see arrows; Fig. $3 c$ and $d$ ). These results suggest that Kpn $\beta 1$-EGFP expressing cells show delayed progression through G1/S and entry into G2/M phase of the cell cycle.

Western blot analysis confirmed that Kpn $\beta 1$ overexpression resulted in a delay in cell cycle progression. After release from the thymidine block, pS10-Histone-H3 (pHisH3) peaked at $10 \mathrm{~h}$ post release in EGFP cells, but remained low throughout the whole time-course in Kpnß1-EGFP cells indicating that the cells did not reach $\mathrm{M}$-phase within $10 \mathrm{~h}$ post release (Fig 3e). Mcl-1 has been previously shown to increase during $\mathrm{S}$ and $\mathrm{G} 2$ phase and peak at mitosis [23], and this same trend was observed in EGFP cells (for the Mcl-1 long isoform; the short isoform was not detected). Kpn $\beta 1$-EGFP cells, however, showed a decrease in expression from the baseline levels observed in asynchronous cells, suggesting that Mcl-1-L may be downregulated or degraded in response to $\mathrm{Kpn} \beta 1$ overexpression. Interestingly, degradation of $\mathrm{Mcl}-1$ has been shown to be induced under a number of cell stress conditions [23, 24].

These results support a central role for $\mathrm{Kpn} \beta 1$ in regulating the proliferation and cell cycle progression of cervical cancer cells, such that when its expression is enhanced, or inhibited $[9,10,25]$, cancer cell proliferation and cell cycle progression is reduced.

\section{Kpn $\beta 1$ overexpression affects cell morphology and actin reorganization}

Due to the negative effects of $K \mathrm{pn} \beta 1$ overexpression on cancer cell proliferation and cell cycle progression, the effects of Kpn $\beta 1$ overexpression on additional biological phenotypes, including cell morphology and actin organization, were next analysed. Phase contrast microscopy of HeLa and CaSki cells stably overexpressing Kpn $\beta 1$ showed distinct changes in cell morphology, with cells becoming smaller and more tightly packed (Fig. 4a, Additional file 1: Figure S1A). Quantification of the changes in cell area showed that Kpn $\beta 1$ overexpression resulted in a significant decrease in cell area when compared to the area of HeLa and CaSki EGFP cells (Fig. 4b, Additional file 1: Figure S1B).

Changes in cell morphology are often driven by rearrangement of the cytoskeleton; thus immunofluorescence actin staining assays were performed using phalloidin, a high-affinity filamentous actin (F-actin) probe, to investigate actin reorganization in HeLa and CaSki cells stably overexpressing Kpn $\beta 1$. Phalloidin staining revealed changes in cell shape, as well as a reduction in the number of actin-rich cytoplasmic extensions seen at the edges of the elongated, spindle-shaped control cells, more evident in HeLa cells (Fig. 4c, Additional file 1: Figure S1C). Quantification of these changes showed that Kpn $\beta 1$ overexpression resulted in a significant decrease in cell area (data not shown), as well as a significant decrease in the number of cytoplasmic protrusions (Fig. 4d, Additional file 1: Figure S1D). This data confirms the changes in cell morphology and size seen using phase contrast microscopy, and suggests that $\mathrm{Kpn} \beta 1$ (or the changes associated with overexpression of $\mathrm{Kpn} \beta 1$ ) plays a role in actin reorganisation. 

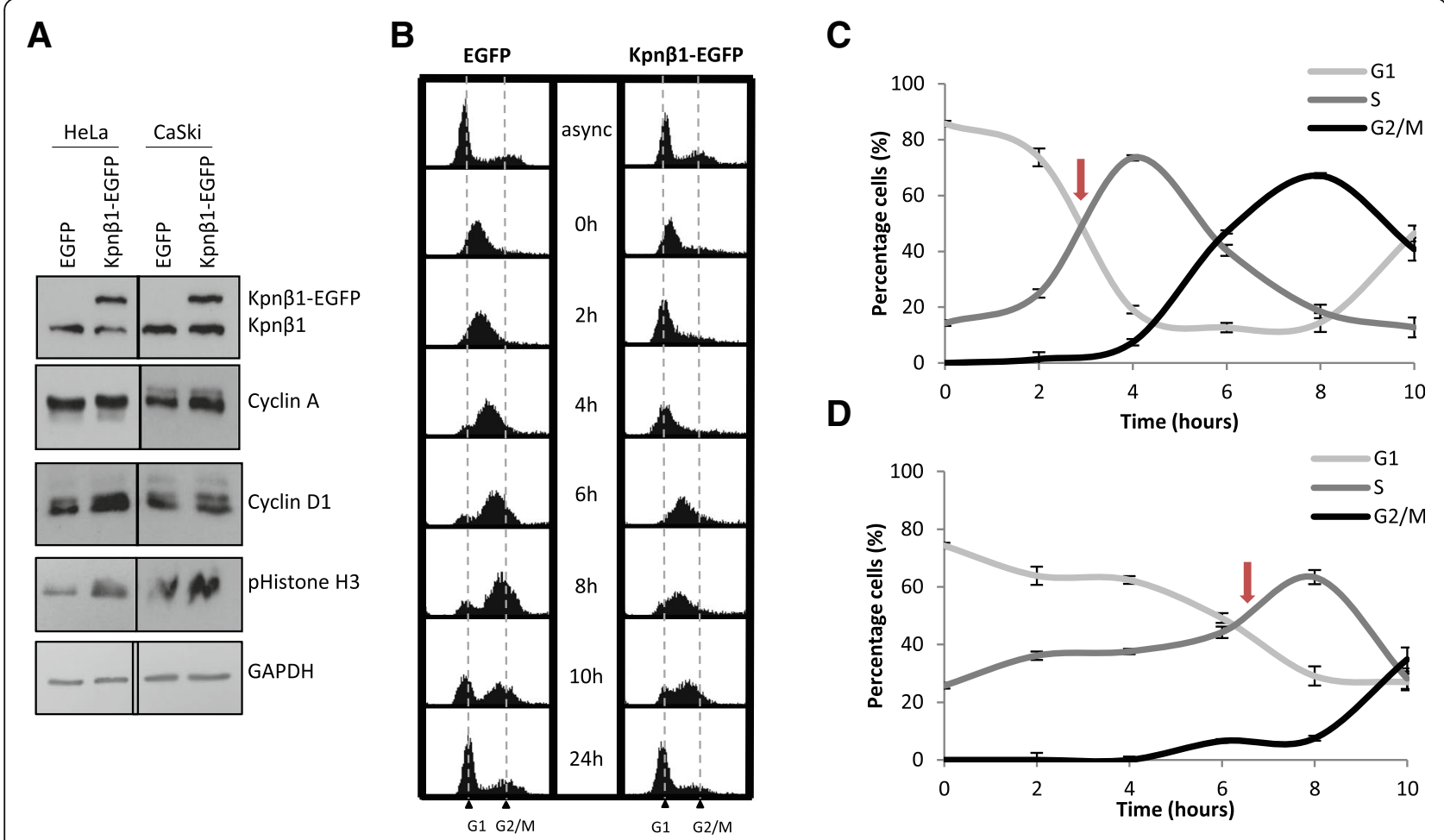

E

EGFP

Kpnß1-EGFP

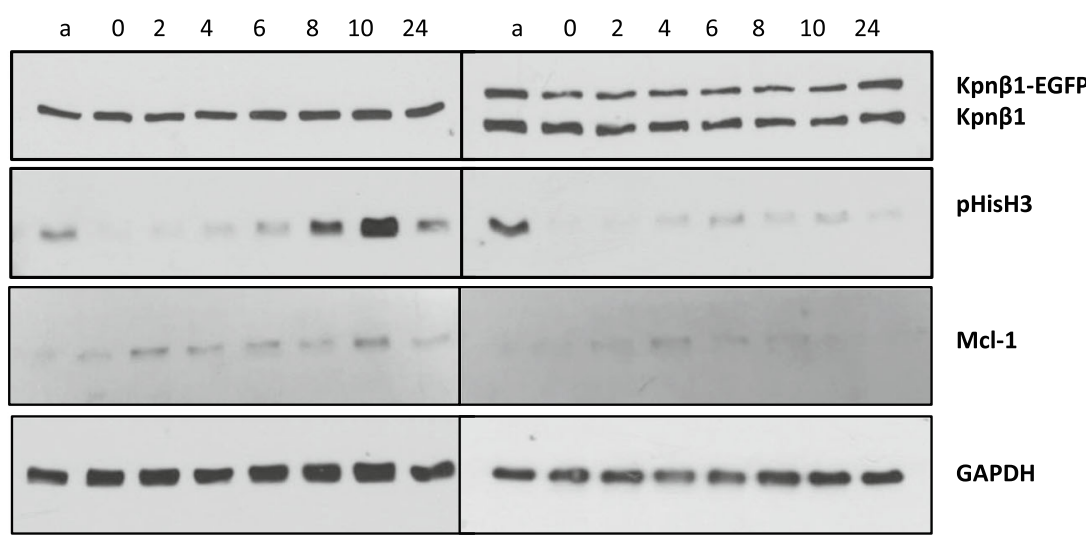

Fig. 3 Overexpression of Kpn $\beta 1$ results in a delay in cell cycle progression. a Protein was harvested from HeLa and CaSki EGFP and Kpnß1-EGFP cells and cell cycle markers investigated by western blot analysis. Cyclin A, cyclin D1 and pHistoneH3 were all expressed at slightly higher levels in the overexpressing cells compared to the EGFP control cells. GAPDH was used to control for protein loading. b Flow cytometric analysis of HeLa EGFP and HeLa Kpnß1-EGFP cells following synchronization into late G1 and release into S phase. Cells were synchronized with 2 mM thymidine, harvested at various time points post release and examined by FACS analysis. An asynchronous culture of cells (async) was used for comparison. $\mathbf{c}$ and $\mathbf{d}$ Line graphs represent quantification of the percentage of cells in each phase of the cell cycle for EGFP (b) and Kpnß1-EGFP (c) cells. Arrows represent the approximate point where $50 \%$ cells had exited the G1 phase. Results shown represent the mean \pm SD. e Western blot analysis was used to determine the expression levels of cell cycle associated proteins at various time points post release following thymidine synchronization, in HeLa EGFP and Kpnß1-EGFP cells. Protein harvested from an asynchronous culture of cells (a) is shown for comparison. GAPDH was used as a control for loading

Overexpression of $\mathrm{Kpn} \beta 1$ results in changes in cell adhesion properties

The observed morphological changes between EGFP and Kpn $\beta 1$-EGFP expressing cells suggests that overexpression of Kpn $\beta 1$ causes cells to pack tighter and form clusters, which indicates the possibility of tight junction formation and increased cell adhesion. Thus, to investigate whether the observed morphological changes were associated with 
A
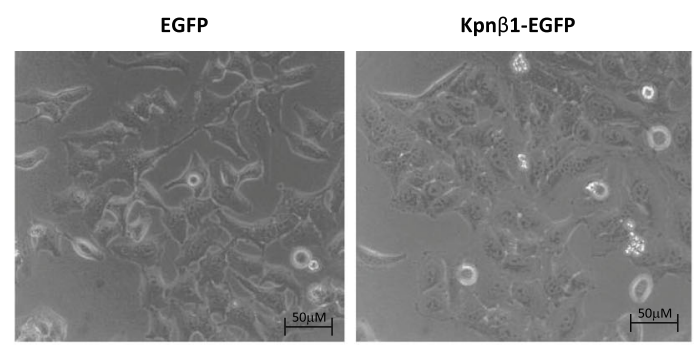

GFP

C
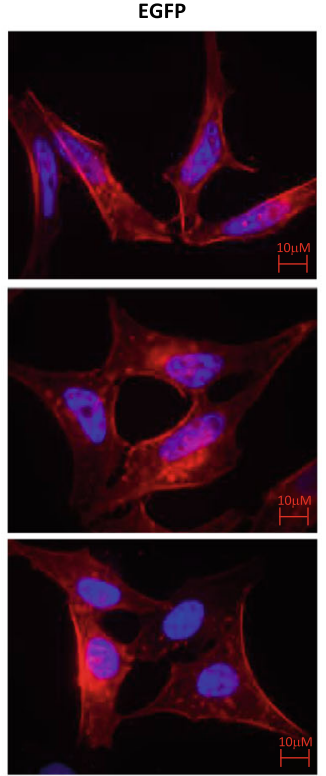

E

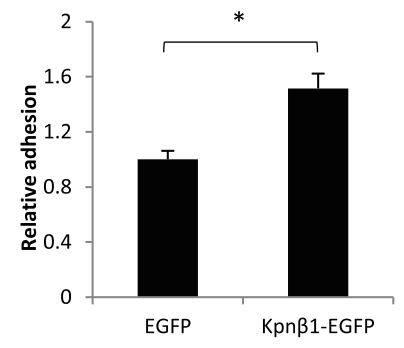

G
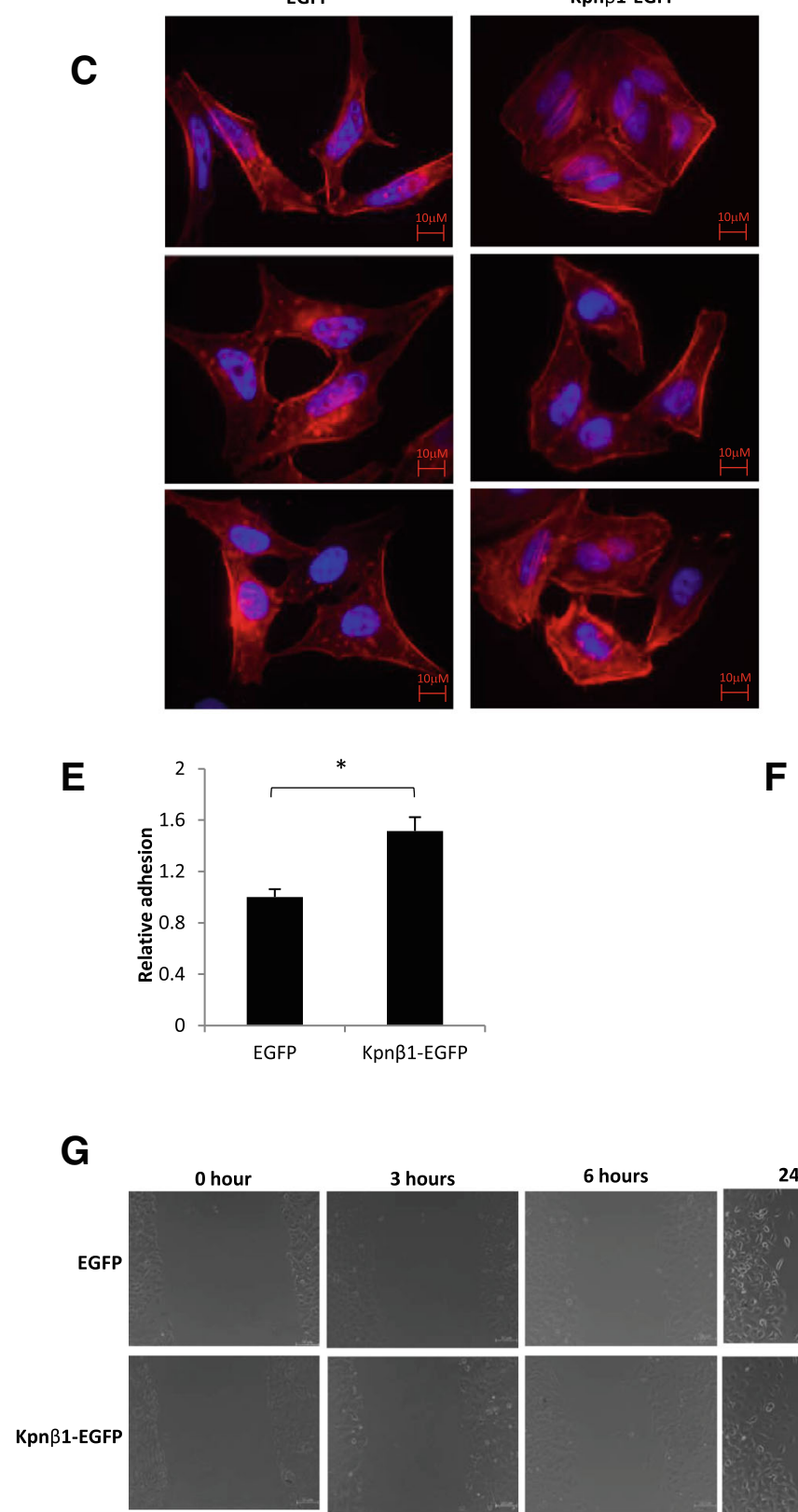

B

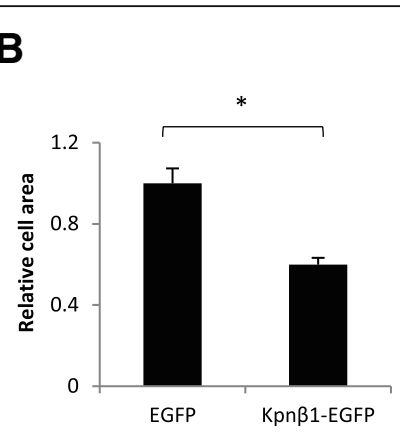

D

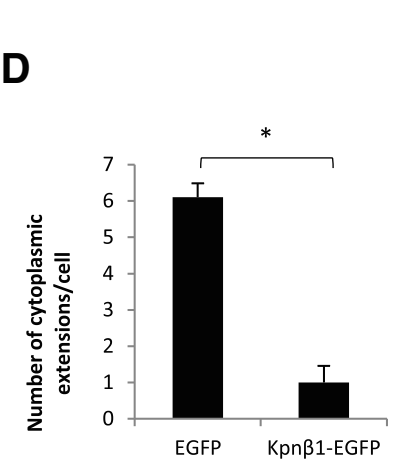

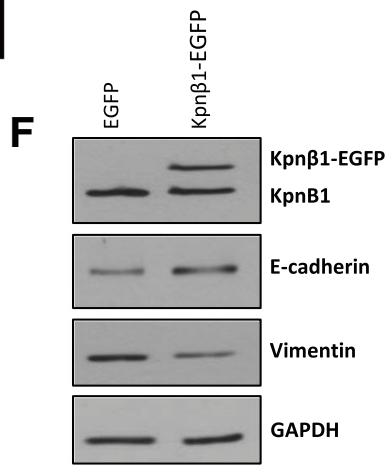

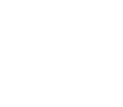


(See figure on previous page.)

Fig. 4 Overexpression of Kpn $\beta 1$ results in changes in the morphology and adhesion properties of cervical cancer cells. a Phase contrast images showing HeLa EGFP and Kpnß1-EGFP cells, taken $48 \mathrm{~h}$ post plating. Cells were viewed at $20 \mathrm{x}$ magnification using the Zeiss Primovert inverted phase microscope. $\mathbf{b}$ Quantification of relative HeLa cell area \pm SEM of forty cells from each condition was performed using the AxioVision 4.7 software $\left({ }^{*} p<0.05\right)$. c Fluorescent staining of polymeric F-actin using phalloidin (red) in EGFP and Kpnß1-EGFP expressing HeLa cells. DAPI stain was used to visualize the cell nuclei (blue). $\mathbf{d}$ Quantification of the number of cytoplasmic protrusions from the captured fluorescent images. Results shown represent the mean \pm SEM over fifteen fields of view $\left({ }^{*} p<0.05\right)$. e Relative cell adhesion of HeLa EGFP and Kpn $\beta 1$-EGFP cells. Adherent cells (on uncoated tissue culture plates) were fixed (after removing non-adherent cells by washing) and stained with $0.5 \%$ crystal violet solution. Cells over ten fields of view, viewed at $10 \times$ magnification, were counted using ImageJ and normalized to unwashed cells. Results shown represent the mean \pm SEM $\left({ }^{*} p<0.05\right)$. $\mathbf{f}$ Western blot analysis showing E-cadherin and Vimentin expression in Kpn $\beta 1$-overexpressing cells. GAPDH was used as a control for loading. $\mathbf{g}$ An in vitro scratch wound healing assay was performed and showed no change in migration of HeLa EGFP and Kpn $\beta 1$-EGFP cells within a $24 \mathrm{~h}$ period. $\mathbf{h}$ Quantification of the scratch wound healing assay in $\mathrm{G}$

any changes in cell adhesion, adhesion assays using uncoated cell culture dishes were used to determine overall changes in the adhesion properties of cells (particularly those involving cell-surface/cell-substrate interactions). Results show that HeLa and CaSki cells overexpressing Kpn $\beta 1$ were significantly more adherent compared to EGFP expressing cells (Fig. 4e, Additional file 1: Figure $\mathrm{S} 1 \mathrm{E})$. Furthermore, the expression levels of various proteins known to be involved in adhesion, such as E-cadherin (plays an important role in promoting cell-cell adhesion [26]), and Vimentin (a marker of mesenchymally derived, non-adherent cells [27]), were also investigated. Western blot analysis revealed that E-cadherin levels were elevated in HeLa and CaSki cells overexpressing Kpn $\beta 1$, while Vimentin levels were decreased (Fig. 4f, Additional file 1: Figure S1F). To determine whether the altered cell adhesion properties and EMT protein profiles of Kpn $\beta 1$-EGFP expressing cells might affect cell migration, a scratch wound healing assay was performed. Interestingly, no change in cell migration was identified in the Kpn $\beta 1$-EGFP compared to control EGFP cells (Fig. 4g, h, Additional file 1: Figure S1G, H). These results suggest that dysregulation of $\mathrm{Kpn} \beta 1$ expression results in altered processes associated with cell-surface (ie. cell to extracellular matrix) and cell-cell adhesion, but does not affect the migration capabilities of cervical cancer cells.

\section{Kpn $\beta 1$ overexpression sensitizes HeLa cells to cisplatin treatment}

Due to the fact that Kpn $\beta 1$ is involved in the nuclear import of proteins involved in apoptosis induced by chemotherapy, such as p53 $[9,28,29]$, and since overexpression of Kpn $\beta 1$ alters the proliferation and cell cycle progression of cervical cancer cells, we next investigated whether Kpn $\beta 1$ overexpression may influence the effectiveness of cisplatin, an anticancer chemotherapy commonly used to treat patients with cervical cancer. To investigate whether upregulation of Kpn $\beta 1$ could alter the response of cancer cells to cisplatin treatment, cisplatin $\mathrm{IC}_{50}$ values were compared in HeLa EGFP and Kpn $\beta 1-E G F P$ cells. The $\mathrm{IC}_{50}$ value for cisplatin was revealed to be $24.9 \mu \mathrm{M}$ in EGFP cells and $13 \mu \mathrm{M}$ in Kpn 31 -EGFP cells, respectively, suggesting that cells overexpressing $\mathrm{Kpn} \beta 1$ have increased sensitivity to cisplatin (Fig. 5A, Additional file 2: Figure S2). Examination of cell viability confirmed these results; a significant decrease in cell viability at various concentrations of cisplatin was observed in cells expressing Kpn $\beta 1$-EGFP compared to those expressing EGFP (Fig. 5B). To determine whether the increased sensitivity to cisplatin treatment observed in cells overexpressing $\mathrm{Kpn} \beta 1$ was associated with increased apoptosis, PARP cleavage after cisplatin treatment in EGFP and Kpn $\beta 1$-EGFP cells was analysed. Western blot analysis revealed enhanced PARP cleavage in cells overexpressing Kpn $\beta 1$ (Kpn $\beta 1$-EGFP) compared to cells expressing EGFP (Fig. 5C), which was confirmed by densitometric analysis (Fig. 5D). The effect of $\mathrm{Kpn} \beta 1$ overexpression on the expression of various proteins that are known to be involved in the cisplatin response was next explored, including p53, p21 and Mcl-1. Examination of p53, p21 and Mcl-1 expression showed that cisplatin treatment lead to a concentration-dependent increase in p53 levels, and a concentration-dependent decrease in p21 and Mcl-1 levels, evident in both EGFP and Kpn 31 -EGFP cells but more prominent in the latter (Fig. 5E). Furthermore, Kpn $\beta 1$-EGFP cells showed higher p53 levels and lower p21 and Mcl-1 levels without cisplatin treatment $(0 \mu \mathrm{M})$. As Kpn $\beta 1$ overexpression has been reported to cause mitotic abnormalities and induce genomic instability [7, 8], we investigated the DNA damage marker $\gamma \mathrm{H} 2 \mathrm{AX}$ after cisplatin treatment in Kpn $\beta 1$-EGFP compared to EGFP cells. Western blot analysis revealed that $\gamma \mathrm{H} 2 \mathrm{AX}$ levels were enhanced upon treatment of Kpn 31 -EGFP cells with cisplatin, indicative of higher levels of DNA damage in cells overexpressing Kpn $\beta 1$ (Fig. 5E).

The upregulation of p53 and downregulation of p21 in the Kpn 31 -EGFP-overexpressing cells, and in response to Cisplatin, warranted further investigation as p21 levels typically follow that of $\mathrm{p} 53$. To further explore the role of these proteins in the cellular response to Cisplatin, their localisation was examined. While p53 was found to be predominately nuclear in the EGFP and Kpn $\beta 1$-EGFP cells, p21 displayed more cytoplasmic localisation (Fig. 5F). p53 and p21 were next inhibited, using Pifithrin $\alpha$ and p21 siRNA respectively, and the effect on Cisplatin 
A

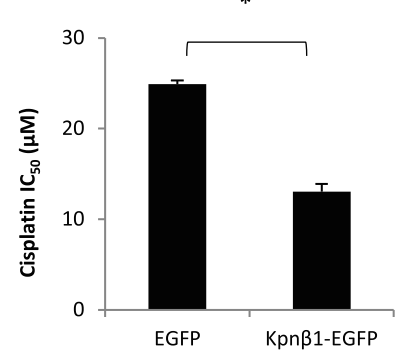

C

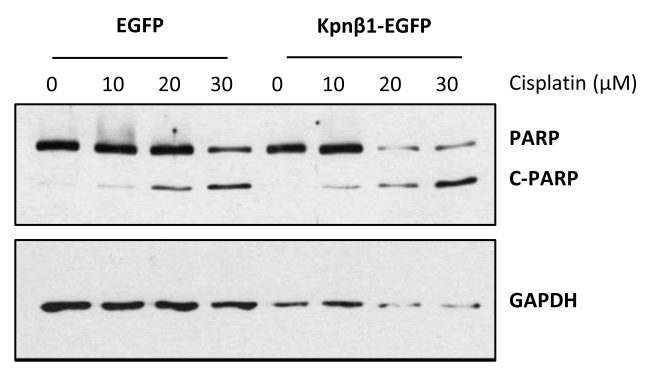

E

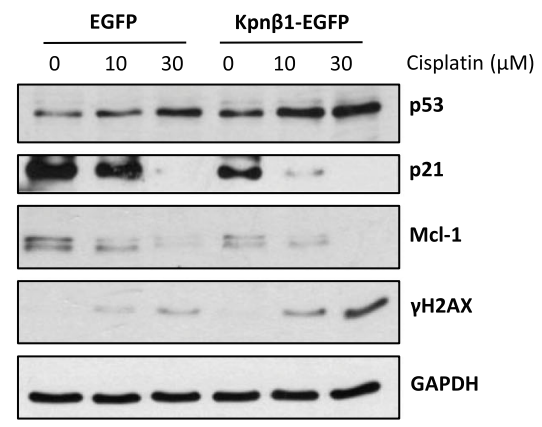

G
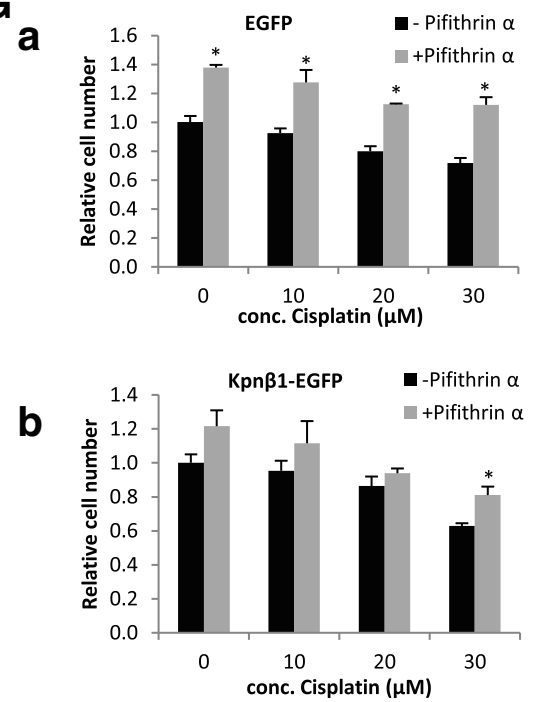

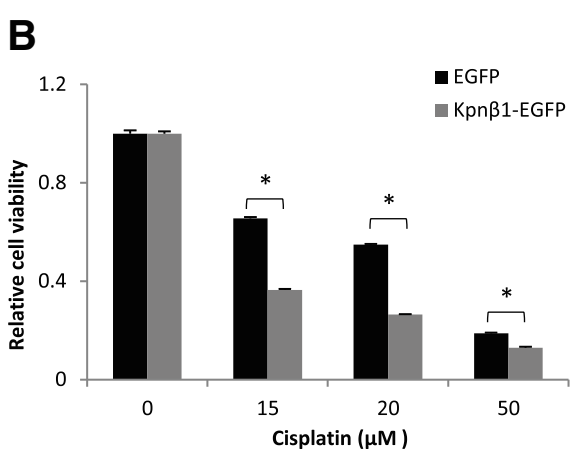

D

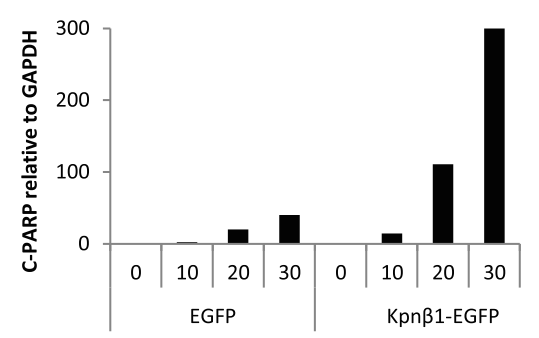

$\mathbf{F}$
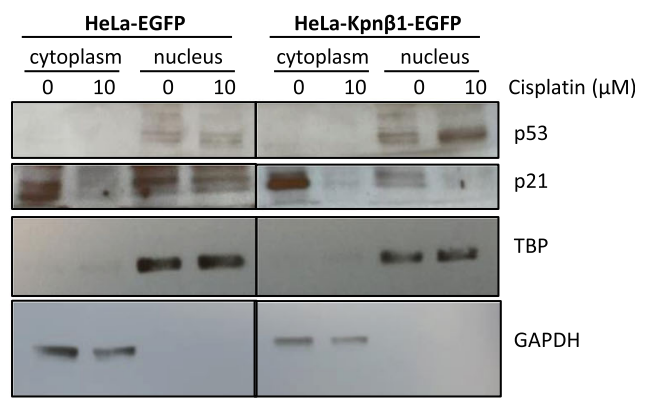

H
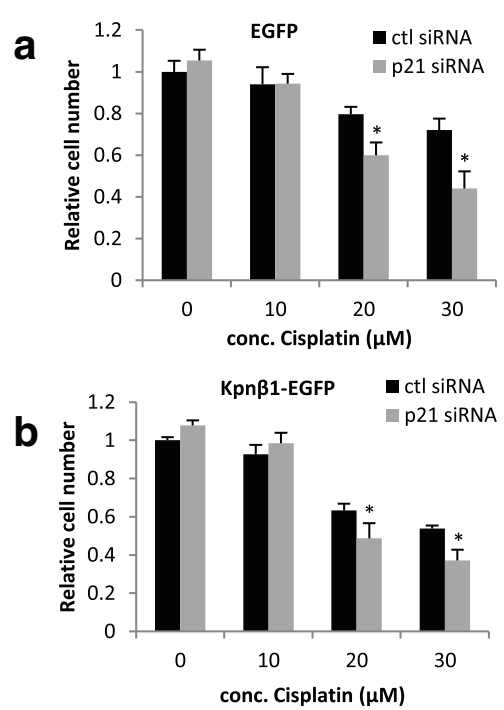

Fig. 5 (See legend on next page.) 


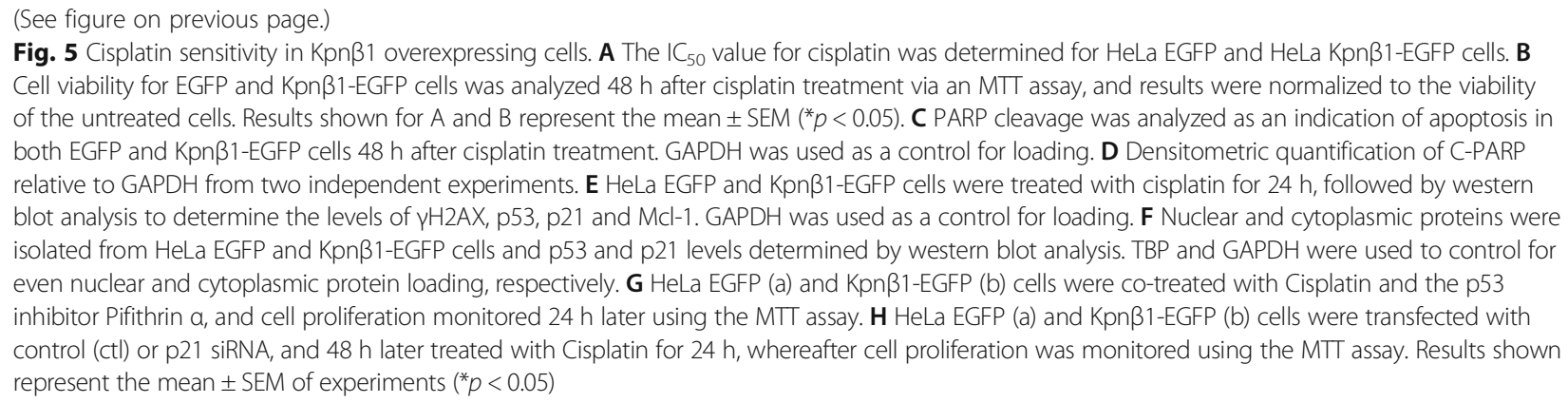

responsiveness monitored by MTT. Interestingly, p53 inhibition resulted in decreased cell death and p21 inhibition resulted in increased cell death in response to Cisplatin (Fig. 5G, H). Similar results were obtained using the CaSki EGFP and Kpn $\beta 1$-EGFP cells (Additional file 3: Figure S3). These results suggest that p53 acts to promote and p21 protect cells from Cisplatin toxicity. The increased sensitivity of Kpn $\beta 1$-EGFP-overexpressing cells to Cisplatin can thus, in part, be explained by the increased p53 and decreased p21 levels in these cells.

\section{Discussion}

Changes in gene expression patterns are a significant driver of cancer progression. Thus, the identification of genes and pathways involved in and/or altered in this process will not only improve our understanding of cancer initiation and development, but will also help in the identification of novel anticancer drug targets. Previous studies have revealed Karyopherin $\beta 1(K p n \beta 1)$, the primary nuclear import protein, to be significantly overexpressed in a variety of cancer types including cervical [10], gastric [30], and breast cancers [13]. Furthermore, these studies reveal that inhibition of $\mathrm{Kpn} \beta 1$ expression leads to cancer cell death, while inhibition in non-cancer cells has only a minor effect on cell viability [10]. These results suggest that Kpn $\beta 1$ has potential as an anticancer therapeutic target, thus warranting further research into the association between Kpn $\beta 1$ expression and cancer progression.

To better understand the role that Kpn $\beta 1$ plays in malignant transformation, we investigated the effects of Kpn $\beta 1$ overexpression on various biological processes associated with cellular transformation. A stable Kpn $\beta 1$ overexpressing cell line was generated and shown to result in enhanced nuclear activity of known Kpn $\beta 1$ cargoes. Surprisingly, this did not translate into an enhanced cancer phenotype as anticipated, but rather suppressed cancer cell proliferation, delayed cell cycle progression, and altered cell morphology and actin reorganization, resulting in increased cell adhesion. This suggests that while overexpression of $\mathrm{Kpn} \beta 1$ is required for the cancer phenotype, further overexpression suppresses the malignancy of cervical cancer cells. This could be due to a number of reasons; such as an imbalance in nuclear import and export, resulting in altered nuclear localisation of cargo proteins whose localisation is critical for cell functioning. Alternatively, upregulation of $\mathrm{Kpn} \beta 1$ could result in increased nuclear import of tumour suppressor proteins; indeed, it has been found that $K p n \beta 1$ overexpression resulted in an increase in the nuclear activity of p53, a known Kpn $\beta 1$ cargo protein [21, 22]. Overexpression of Kpn $\beta 1$ may also result in the increased nuclear import of various other cell cycle proteins that are Kpn $\beta 1$ cargoes, such as cyclin B1 and cyclin E [31], whose altered localisation could greatly impact cell cycle progression. Interestingly, Kpn $\beta 1$ overexpression did not result in an increase in cell death in these cells, therefore the effects seen were due a reduction in rate of proliferation rather than an induction of cell death. Ultimately, the nuclear transport process is a tightly regulated process that is critical for cell functioning. Altering this process, by increasing the expression of $\mathrm{Kpn} \beta 1$ alone, has negative cellular consequences for cervical cancer cells.

Normal cells overexpressing Kpn $\beta 1$ also displayed reduced cell proliferation, suggesting that $K p n \beta 1$ alone is insufficient to promote cancer behaviour. In contrast to our results, Kodama et al. (2017) showed that stable overexpression of $\mathrm{Kpn} \beta 1$ in ovarian cancer cells resulted in a significant increase in cell proliferation, and these authors suggest that Kpn $\beta 1$ acts as an oncogene [32]. It is possible that the effects observed due to $\mathrm{Kpn} \beta 1$ overexpression may be specific to different cell types, and are likely subject to the levels of endogenous Kpn $\beta 1$ present in certain cell lines. Furthermore, while we show that the overexpressed Kpn $\beta 1$ in our study is functional, in that it results in the increased nuclear activity of Kpn $\beta 1$ cargoes, it is possible that the EGFP tag, fused to its C-terminus, may alter $\mathrm{Kpn} \beta 1$ function or its ability to bind interaction partners, compared to the tag-less Kpn $\beta 1$ overexpressed by Kodama et al. (2017), hence contribute to the discrepancies between studies.

While Kpn $\beta 1$ overexpression alone appears to be insufficient to induce any of the biological phenotypes associated with cellular transformation, overexpression of additional members of the nuclear transport machinery may be required for cancer-associated changes. It is 
possible that in terms of nuclear import, cancer cells have already reached their maximum capability and thus further enhancement of various factors such as Kpn $\beta 1$, without strict control and regulation of all factors involved in nuclear transport (i.e. a precise balance), results in further cellular dysfunction.

A wide range of cancer processes have been shown to rely on Kpn $\beta 1$-mediated nuclear import. For example, a recent review shows how the Karyopherin proteins are involved in controlling a large number of epithelial-mesenchymal transition (EMT) promoting pathways [33]. $\mathrm{Kpn} \beta 1$ has been shown to be involved in the nuclear translocation of a number of EMT-promoting proteins including Snail [34], Smad [35], and Notch [36], all of which play a role in increasing cancer cell invasion and metastasis. In addition to this, $\mathrm{Kpn} \beta 1$ has also been shown to play a role in actin cytoskeleton regulation, by regulating the interaction between an actin binding kine$\sin$ (NabKin) and F-actin, demonstrating that Kpn $\beta 1$ likely plays a role in influencing cytoskeletal elements and structure $[6,37]$. We showed that $\mathrm{Kpn} \beta 1$ overexpression resulted in changes in cell morphology and actin reorganisation, with cells becoming smaller and more epithelial-like. In addition, Kpn $\beta 1$ overexpressing cells showed enhanced adhesion, as well as an increase in E-cadherin and decrease in Vimentin protein expression. These results suggest that overexpression of $K p n \beta 1$ results in a mesenchymal-to-epithelial transition (MET), where cells transition from motile, more spindle-shaped mesenchymal cells to adherent, more compact/columnar epithelial cells. There is much evidence linking the EMT process with tumour progression and malignant transformation, as transitioning to a more mesenchymal state promotes cell invasion and metastasis (or cancer cell dissemination) [38]. More recently, evidence has started to emerge supporting the concept that MET may be important for metastatic colonization, but research remains limited. Thus, it appears that overexpression of Kpn $\beta 1$, beyond that which is already elevated, has negative consequences for the proliferation, progression and metastatic potential of cancer cells.

To identify whether overexpression of $\mathrm{Kpn} \beta 1$ resulted in any changes to the cancer cell response to cisplatin treatment, HeLa EGFP and Kpnß1-EGFP cells were treated with cisplatin and the effects on various processes observed, including cell viability and apoptosis. Our results revealed that Kpn $\beta 1$ overexpressing HeLa cells showed significantly reduced viability after treatment with cisplatin, and were more prone to cisplatin-induced apoptosis when compared to HeLa EGFP cells. This could be due to enhanced nuclear import of cargo proteins required for the apoptotic process, for example p53 [9, 28, 29]. p53 is involved in the activation of apoptosis induced by DNA-damaging agents, such as cisplatin [39]. We showed that HeLa cells overexpressing Kpn $\beta 1$ showed higher levels of p53 when treated with cisplatin, compared to cells expressing EGFP, and that the same trend in expression was seen with the DNA damage marker, $\gamma \mathrm{H} 2 \mathrm{AX}$. Examination of the expression levels of anti-apoptotic proteins p21 and Mcl-1, revealed that both proteins were reduced in response to cisplatin treatment, and the reduction was more prominent in cells overexpressing $\mathrm{Kpn} \beta 1$, suggesting that these cells are more sensitive to apoptotic signals. We also showed that stable overexpression of $\mathrm{Kpn} \beta 1$ in synchronized HeLa cells resulted in a decrease in (or degradation of) Mcl-1 expression. Interestingly, a number of recent studies have shown that inhibition of Mcl-1 expression sensitizes cancer cells to cisplatin-induced apoptosis [40, 41]. We show that p21 inhibition sensitises cervical cancer cells to cisplatin treatment, which is in agreement with other studies showing that knockdown or inhibition of p21 expression significantly increases apoptosis of ovarian cancer and testicular cancer cells induced by cisplatin $[42,43]$. On the other hand, other studies have reported p21 overexpression to increase Cisplatin sensitivity in lung adenocarcinoma cells [44, 45] and osteosarcoma cells [46], thus it is clear that different cancer cells use different cellular mechanisms to govern Cisplatin responsiveness. We also show that despite the HPV positive nature of HeLa and CaSki cells (and thus low p53 activity), p53 inhibition reduces cervical cancer cell sensitivity to Cisplatin, suggesting a role for p53 in mediating Cisplatin-induced cell death. This is corroborated by other studies, which show a role for p53 in Cisplatin-induced apoptosis [47]. However, p53, like p21, can exert anti-apoptotic effects in response to Cisplatin in other contexts [48]. Taken together, in our study, p53 and p21 enhance and protect cervical cancer cells from Cisplatin-induced cell death, respectively, thus the higher p53 and lower p21 in the Kpnß1-EGFP-overexpressing cells likely contributes, at least in part, to the increased sensitivity of these cells to Cisplatin. Interestingly, Kodama et al. (2017) recently showed that inhibition of $\mathrm{Kpn} \beta 1$ expression, in combination with paclitaxel treatment, synergistically reduced cell proliferation/viability in ovarian cancer cells [32].

Whilst we have previously shown that Kpn $\beta 1$ inhibition, genetically or pharmacologically, resulted in an induction of cervical cancer cell death and the appearance of mitotic defects $[9,10,25]$, others have reported that exogenously expressed Kpn $\beta 1$ induced mitotic abnormalities, resulting in genomic instability $[7,8]$. We report that $\mathrm{Kpn} \beta 1$ overexpression results in increased levels of pSer10 Histone H3 in asynchronous cells, and delays cell cycle progression into G2/M in cells released from a thymidine block, suggesting that mitotic processes are somewhat impaired in these cells. However, further overexpression of Kpn $\beta 1$-EGFP, beyond that achieved in this study, resulted in distinct mitotic defects 
and cell death (data not shown), further reinforcing that $\mathrm{Kpn} \beta 1$ overexpression is detrimental to cervical cancer cell biology. It is likely that cancer cells require a precise balance of $\mathrm{Kpn} \beta 1$ expression, and that perturbation of this balance in either direction has deleterious effects on cancer cell survival.

\section{Conclusion}

To our knowledge this is the first study to show that overexpression of $\mathrm{Kpn} \beta 1$ provides no growth advantage to cervical cancer cells or non-cancer epithelial cells. In fact, when $K p n \beta 1$ is overexpressed in cervical cancer cells, negative effects associated with a variety of biological processes are observed, including reduced cell proliferation, delayed cell cycle progression, altered cellular morphology, and increased cellular adhesion. Furthermore, Kpn $\beta 1$ overexpression enhances cervical cancer cell sensitivity to cisplatin, mediated via increased p53 and decreased p21 protein levels. Ultimately, it appears as if a tight regulation of $K p n \beta 1$ is essential for the correct functioning of cancer cells and for the responsiveness of these cells to chemotherapeutic agents, like Cisplatin.

\section{Additional files}

\section{Additional file 1: Figure S1. Overexpression of $K p n \beta 1$ results in} changes in the morphology and adhesion properties of CaSki cervical cancer cells. A: Phase contrast images showing CaSki EGFP and Kpnß1EGFP cells, taken $48 \mathrm{~h}$ post plating. Cells were viewed at $20 \times$ magnification using the Zeiss Primovert inverted phase microscope. B: Quantification of relative CaSki cell area \pm SEM of forty cells from each condition was performed using the AxioVision 4.7 software $\left({ }^{*} p<0.05\right)$. C: Fluorescent staining of polymeric F-actin using phalloidin (red) in EGFP and Kpn $\beta 1$-EGFP expressing CaSki cells. DAPI stain was used to visualize the cell nuclei (blue). D: Quantification of the number of cytoplasmic protrusions from the captured fluorescent images. Results shown represent the mean \pm SEM over fifteen fields of view $\left({ }^{*} p<0.05\right)$. E: Relative cell adhesion in CaSki EGFP and Kpn 31 -EGFP cells. Adherent cells were fixed (after removing non-adherent cells by washing) and stained with $0.5 \%$ crystal violet solution. Cells over ten fields of view, viewed at $10 \times$ magnification, were counted using ImageJ and normalized to unwashed cells. Results shown represent the mean \pm SEM $\left({ }^{*} p<0.05\right)$. F: Western blot analysis was used to determine the expression levels of E-cadherin and Vimentin in CaSki Kpnß1-overexpressing cells. GAPDH was used as a control for loading. G: An in vitro scratch wound healing assay was performed and showed no change in migration of CaSki EGFP and Kpnß1-EGFP cells within a $24 \mathrm{~h}$ period. $\mathbf{H}$ : Quantification of the scratch wound healing assay in G. (PPTX 627 kb)

Additional file 2: Figure S2. Overexpression of $K p n \beta 1$ results in increased sensitivity to Cisplatin. Dose-response curves are shown after treatment of HeLa EGFP- and HeLa Kpn $\beta 1$-EGF-expressing cells with Cisplatin. (PPTX $42 \mathrm{~kb}$ )

Additional file 3: Figure S3. p53 and p21 inhibition reduces and enhances CaSki EGFP and Kpn $\beta 1$-EGFP cell sensitivity to Cisplatin, respectively. A: CaSki EGFP (a) and Kpnß1-EGFP (b) cells were co-treated with Cisplatin and the p53 inhibitor Pifithrin $a$, and cell proliferation monitored $24 \mathrm{~h}$ later using the MTT assay. B: CaSki EGFP (a) and Kpnß1-EGFP (b) cells were transfected with control (ctl) or p21 siRNA, and $48 \mathrm{~h}$ later treated with Cisplatin for $24 \mathrm{~h}$, whereafter cell proliferation was monitored using the MTT assay. Results shown represent the mean \pm SEM of experiments ( $\left.{ }^{*} p<0.05\right)$. (PPTX $59 \mathrm{~kb}$ )

\section{Abbreviations}

ATCC: American Type Culture Collection; CANSA: Cancer Association of South Africa; cNLS: Classical NLS; Ctl: Control; DMEM: Dulbecco's Modified Eagle's Medium; EMT: Epithelial-to-mesenchymal transition; Factin: Filamentous actin; FCS: Fetal Calf Serum; IRES: Internal ribosome entry site; Kpna: Karyopherin a; Kpnß1: Karyopherin $\beta 1$; MET: Mesenchymal-toepithelial transition; NLS: Nuclear localisation sequence; NPC: Nuclear pore complex; Nups: Nucleoporins; pHisH3: PS10-Histone-H3

\section{Acknowledgements}

Not applicable.

\section{Funding}

This work was supported by funding from the South African Medical Research Council, the National Research Foundation, the Cancer Association of South Africa (CANSA), and the University of Cape Town. The funding body had no role in the design of the study and collection, analysis and interpretation of data and in writing the manuscript.

\section{Availability of data and materials}

Data sharing is not applicable to this article as no datasets were generated or analysed during the current study.

\section{Authors' contributions}

SC, PvdW, AC, AAS and KH performed experiments. SC, PvdW, AC, AAS and $V L$ analysed and interpreted the data. SC wrote the manuscript, with editing from PvdW, VL and $\mathrm{KH}$. VL obtained the research funding for the study. All authors read and approved the final manuscript and have agreed to be accountable for all aspects of the work.

Ethics approval and consent to participate

Not applicable.

Consent for publication

Not applicable.

\section{Competing interests}

The authors declare that they have no competing interests.

\section{Publisher's Note}

Springer Nature remains neutral with regard to jurisdictional claims in published maps and institutional affiliations.

Received: 11 April 2018 Accepted: 5 November 2018

Published online: 16 November 2018

\section{References}

1. Mosammaparast N, Pemberton LF. Karyopherins: from nuclear-transport mediators to nuclear-function regulators. Trends Cell Biol. 2004;14:547-56.

2. Görlich D, Henklein P, Laskey RA, Hartmann E. A 41 amino acid motif in importin-alpha confers binding to importin-beta and hence transit into the nucleus. EMBO J. 1996;15:1810-7.

3. Freitas N, Cunha C. Mechanisms and signals for the nuclear import of proteins. Curr Genomics. 2009;10:550-7.

4. Moroianu J, Blobel G, Radu A. Nuclear protein import: ran-GTP dissociates the karyopherin alphabeta heterodimer by displacing alpha from an overlapping binding site on beta. Proc Natl Acad Sci U S A. 1996;93:7059-62.

5. Harel A, Forbes DJ. Importin beta: conducting a much larger cellular symphony. Mol Cell. 2004;16:319-30.

6. Forbes DJ, Travesa A, Nord MS, Bernis C. Nuclear transport factors: global regulation of mitosis. Curr Opin Cell Biol. 2015;35:78-90.

7. Ciciarello M, Mangiacasale R, Thibier C, Guarguaglini G, Marchetti E, Di Fiore $B$, et al. Importin beta is transported to spindle poles during mitosis and regulates ran-dependent spindle assembly factors in mammalian cells. J Cell Sci. 2004;117:6511-22. 
8. Roscioli E, Di Francesco L, Bolognesi A, Giubettini M, Orlando S, Harel A, et al. Importin- $\beta$ negatively regulates multiple aspects of mitosis including RANGAP1 recruitment to kinetochores. J Cell Biol. 2012;196:435-50.

9. Angus L, van der Watt PJ, Leaner VD. Inhibition of the nuclear transporter, $K p n \beta 1$, results in prolonged mitotic arrest and activation of the intrinsic apoptotic pathway in cervical cancer cells. Carcinogenesis. 2014;35:1121-31.

10. van der Watt PJ, Maske CP, Hendricks DT, Parker MI, Denny L, Govender D, et al. The Karyopherin proteins, $\mathrm{Crm} 1$ and Karyopherin $\beta 1$, are overexpressed in cervical cancer and are critical for cancer cell survival and proliferation. Int J Cancer. 2009;124:1829-40.

11. Kuusisto HV, Wagstaff KM, Alvisi G, Roth DM, Jans DA. Global enhancement of nuclear localization-dependent nuclear transport in transformed cells. FASEB J. 2012:26:1181-93.

12. Smith ER, Cai KQ, Smedberg JL, Ribeiro MM, Rula ME, Slater C, et al. Nuclear entry of activated MAPK is restricted in primary ovarian and mammary epithelial cells. PLoS One. 2010;5:1-9.

13. Kuusisto HV, Jans DA. Hyper-dependence of breast cancer cell types on the nuclear transporter importin $\beta 1$. Biochim Biophys Acta. 1853;2015:1870-8.

14. Hobbs S, Jitrapakdee S, Wallace JC. Development of a Bicistronic vector driven by the human polypeptide chain elongation factor 1a promoter for creation of stable mammalian cell lines that express very high levels of recombinant proteins. Biochem Biophys Res Commun. 1998;252:368-72.

15. Beals CR, Clipstone NA, Ho SN, Crabtree GR. Nuclear localization of NF-ATC by a calcineurin-dependent, cyclosporin-sensitive intramolecular interaction. Genes Dev. 1997;11:824-34.

16. Ichida M, Finkel T. Ras regulates NFAT3 activity in cardiac myocytes. J Biol Chem. 2001;276:3524-30.

17. Maritz MF, van der Watt PJ, Holderness N, Birrer MJ, Leaner VD. Inhibition of AP-1 suppresses cervical cancer cell proliferation and is associated with p21 expression. Biol Chem. 2011;392:439-48.

18. el-Deiry WS, Tokino T, Velculescu VE, Levy DB, Parsons R, Trent JM, et al. WAF1, a potential mediator of p53 tumor suppression. Cell. 1993;75:817-25.

19. Forwood JK, Lam MHC, Jans DA. Nuclear import of Creb and AP-1 transcription factors requires importin- $\beta 1$ and ran but is independent of importin-a. Biochemistry. 2001;40:5208-17.

20. Liang $P$, Zhang $H$, Wang G, Li S, Cong S, Luo Y, et al. KPNB1, XPO7 and IPO8 mediate the translocation of NF-kB/p65 into the nucleus. Traffic. 2013;14:1132-43.

21. Liang SH, Clarke MF. A bipartite nuclear localization signal is required for p53 nuclear import regulated by a carboxyl-terminal domain. J Biol Chem. 1999:274:32699-703.

22. Kim I, Kim D, Han S, Chin M, Nam H, Cho H, et al. Truncated form of importin a identified in breast Cancer cell inhibits nuclear import of p53. J Biol Chem. 2000;275:23139-45.

23. Harley ME, Allan LA, Sanderson HS, Clarke PR. Phosphorylation of mcl-1 by CDK1-cyclin B1 initiates its Cdc20-dependent destruction during mitotic arrest. EMBO J. 2010;29:2407-20.

24. Nijhawan D, Fang M, Traer E, Zhong Q, Gao W, Du F, et al. Elimination of $\mathrm{mcl}-1$ is required for the initiation of apoptosis following ultraviolet irradiation. Genes Dev. 2003:17:1475-86.

25. van der Watt PJ, Chi A, Stelma T, Stowell C, Strydom E, Carden S, et al. Targeting the nuclear import receptor $\mathrm{Kpn} \beta 1$ as an anticancer therapeutic. Mol Cancer Ther. 2016;15:560-73.

26. van Roy F, Berx G. The cell-cell adhesion molecule E-cadherin. Cell Mol Life Sci. 2008;65:3756-88.

27. Kidd ME, Shumaker DK, Ridge KM. The role of vimentin intermediate filaments in the progression of lung Cancer. Am J Respir Cell Mol Biol. 2014;50:1-6.

28. Johnstone RW, Ruefli AA, Lowe SW. Apoptosis: a link between cancer genetics and chemotherapy. Cell. 2002;108:153-64.

29. Seitz SJ, Schleithoff ES, Koch A, Schuster A, Teufel A, Staib F, et al. Chemotherapy-induced apoptosis in hepatocellular carcinoma involves the p53 family and is mediated via the extrinsic and the intrinsic pathway. Int J Cancer. 2010;126:2049-66.

30. Zhu J, Wang Y, Huang H, Yang Q, Cai J, Wang Q, et al. Upregulation of KPNB1 in gastric cancer cell promotes tumor cell proliferation and predicts poor prognosis. Tumor Biol. 2016;37:661-72.

31. Moore JD, Yang J, Truant R, Kornbluth S. Nuclear import of Cdk/cyclin complexes: identification of distinct mechanisms for import of Cdk2/cyclin E and Cdc2/cyclin B1. J Cell Biol. 1999;144:213-24.

32. Kodama M, Kodama T, Newberg JY, Katayama H, Kobayashi M, Hanash SM, et al. In vivo loss-of-function screens identify KPNB1 as a new druggable oncogene in epithelial ovarian cancer. Proc Natl Acad Sci. 2017;114:E7301-10.
33. Azmi AS. Unveiling the role of nuclear transport in epithelial-tomesenchymal transition. Curr Cancer Drug Targets. 2013:13:906-14.

34. Yamasaki H, Sekimoto T, Ohkubo T, Douchi T, Nagata Y, Ozawa M, et al. Zinc finger domain of snail functions as a nuclear localization signal for importin $\beta$-mediated nuclear import pathway. Genes Cells. 2005;10:455-64.

35. Hill CS. Nucleocytoplasmic shuttling of Smad proteins. Cell Res. 2009;19:36-46.

36. Huenniger K, Krämer A, Soom M, Chang I, Köhler M, Depping R, et al. Notch1 signaling is mediated by importins alpha 3, 4, and 7. Cell Mol Life Sci. 2010;67:3187-96.

37. Samwer M, Dehne H-J, Spira F, Kollmar M, Gerlich DW, Urlaub H, et al. The nuclear F-actin interactome of Xenopus oocytes reveals an actin-bundling kinesin that is essential for meiotic cytokinesis. EMBO J. 2013;32:1886-902.

38. Larue L, Bellacosa A. Epithelial-mesenchymal transition in development and cancer: role of phosphatidylinositol 3' kinase/AKT pathways. Oncogene. 2005:24:7443-54.

39. Han JY, Chung YJ, Park SW, Kim JS, Rhyu MG, Kim HK, et al. The relationship between cisplatin-induced apoptosis and p53, bcl-2 and bax expression in human lung cancer cells. Korean J Intern Med. 1999;14:42-52.

40. Zhang F, Shen M, Yang L, Yang X, Tsai Y, Keng PC, et al. Simultaneous targeting of ATM and mcl-1 increases cisplatin sensitivity of cisplatinresistant non-small cell lung cancer. Cancer Biol Ther. 2017;18:606-15.

41. Yu X, Li W, Xia Z, Xie L, Ma X, Liang Q, et al. Targeting MCL-1 sensitizes human esophageal squamous cell carcinoma cells to cisplatin-induced apoptosis. BMC Cancer. 2017:17:449.

42. Xia X, Ma Q, Li X, Ji T, Chen P, Xu H, et al. Cytoplasmic p21 is a potential predictor for cisplatin sensitivity in ovarian cancer. BMC Cancer. 2011;11:399.

43. Koster R, di Pietro A, Timmer-Bosscha H, Gibcus JH, van den Berg A, Suurmeijer AJ, et al. Cytoplasmic p21 expression levels determine cisplatin resistance in human testicular cancer. J Clin Invest. 2010;120:3594-605.

44. Liu Z, Sun M, Lu K, Liu J, Zhang M, Wu W, et al. The long noncoding RNA HOTAIR contributes to cisplatin resistance of human lung adenocarcinoma cells via downregualtion of p21WAF1/CIP1 expression. PLoS One. 2013;8:1-15.

45. Wang H, Zhu LJ, Yang YC, Wang ZX, Wang R. MiR-224 promotes the chemoresistance of human lung adenocarcinoma cells to cisplatin via regulating G1/S transition and apoptosis by targeting p21 WAF1/CIP1. Br J Cancer. 2014;111:339-54

46. Ding $Y$, Wang $Y$, Chen J, Hu Y, Cao Z, Ren P, et al. P21 overexpression sensitizes osteosarcoma U2OS cells to cisplatin via evoking caspase-3 and Bax/BCl-2 cascade. Tumor Biol. 2014:35:3119-23.

47. Wesierska-Gadek J, Schloffer D, Kotala V, Horky M. Escape of p53 protein from E6-mediated degradation in HeLa cells after cisplatin therapy. Int J Cancer. 2002:101:128-36.

48. Di Pietro A, Koster R, Boersma-van Eck W, Dam WA, Mulder NH, Gietema JA, et al. Pro- and anti-apoptotic effects of p53 in cisplatin-treated human testicular cancer are cell context-dependent. Cell Cycle. 2012;11:4552-62.

Ready to submit your research? Choose BMC and benefit from:

- fast, convenient online submission

- thorough peer review by experienced researchers in your field

- rapid publication on acceptance

- support for research data, including large and complex data types

- gold Open Access which fosters wider collaboration and increased citations

- maximum visibility for your research: over $100 \mathrm{M}$ website views per year

At $\mathrm{BMC}$, research is always in progress.

Learn more biomedcentral.com/submissions 